\title{
Renewable and durable building materials
}

\author{
L. Brock \\ School of Architecture, \\ Landscape Architecture University of British Columbia, Canada
}

\begin{abstract}
Present ecological circumstances call for severe and immediate action. The debates that raged in Copenhagen at the United Nation's Climate Change Conference in 2009 spoke to the enormity of the problem as well as the complexity of the solutions. While many initiatives have begun to create public awareness and, in a few cases, have had a minor effect on decreasing our continuing consumption of natural resources, it is not nearly enough. The construction, occupation, and disposal of buildings should be a critical focus of any discussion on sustainability. This paper explores the efficacy of renewable building materials used in construction in Canada and the United States. The discussion centres on two examples, engineered wood products and earthen blocks. This paper assumes that the durability or long-life of the material in service is a key component to sustainability and that the construction of housing has a substantial role to play. The emphasis is on materials used in the building envelope or structure.
\end{abstract}

Keywords: sustainability, renewable resources, durability, LEED ${ }^{\circledR}$, engineered wood, adobe, pressed earth blocks.

\section{Introduction}

University of British Columbia professor William Reese wrote about our "massdelusion in consumer culture," arguing, "that most mainstream approaches to sustainability today - hybrid cars, green buildings, smart growth, the new urbanism, green consumerism - do not, in fact, address the fundamental problem. Instead, they attempt to reproduce the status quo by other means. Consistent with our prevailing cultural illusion, today's global society essentially equates sustainability with maintaining growth through technological innovation and greater material and economic efficiency." [1] 
Ed Mazria, founder of Architecture 2030, points out that, "Architecture consumes approximately 48 percent of all the U.S. energy produced and is responsible for 46 percent of all U.S. CO2 emissions annually, almost double any other sector. It's also the fastest growing energy-consuming and emissions sector." [2]. Buildings are around a long time, often 50 to 100 years or more, making changes to their construction critical. A point missed by Mazria in his seminal article, titled "It's the Architecture Stupid!" is that the majority of the construction dollar goes into housing and architects do not design most housing. It is estimated that in the developed world "perhaps 80 percent [of buildings] by value, are not designed by architects... and most of that 80 percent are houses." [3]. Consequently a change made in the housing market resonates more quickly and has a greater effect than those made in the non-residential market even though this is often where experimentation is occurring.

\section{Sustainability and durability}

Durability is of upmost importance in the design and construction of sustainable buildings and the building envelope is where most failures occur. LEED $\AA$, the third party energy rating system developed by the U.S. Green Building Council (USGBC) in 2000, does not presently give points for durability or reduced life cycle costs. In the catalogue of possible points for Innovation in Design the one that comes closest to producing a more durable building is for a "preventative maintenance program." USGBC has an on-going working committee looking at introducing Life Cycle Analysis (LCA) into LEED ${ }^{2}$, but it is a difficult task, the ideal being on-going, whole building modelling for energy consumption. But equally important is durability of the component parts and assemblies. A cladding system that lasts 30 years will have half the embodied energy and contribute half of the demolition waste as a cladding that lasts only 15 years. Failing claddings can also affect the thermal properties of the wall and hasten the failure of all wall components. Durability is difficult to compute and often has less to do with the material than with the protection of the assembly particularly from moisture and differential movement.

When LEED ${ }^{\circledR}$ Canada was initiated in 2003 a single point was introduced for durability. The intent was to: "Minimize materials use and construction waste over a building's life resulting from premature failure of the building and its constituent components and assemblies." The durability point references the Canadian Standards Association's document titled Guidelines on Durability in Buildings (S478-95, reaffirmed 2001), an important guideline. As in the U.S. one or two more points are possible with innovative design. While the steps taken by Canada are admirable, the onerous paperwork involved means that these points are often ignored. It is simpler to add a bike rack or use bamboo flooring for a point. If the durability point were a requirement for all LEED ${ }^{\circledR}$ accredited buildings in the United States and Canada our buildings would last longer. Both Canada and the U.S. have introduced LEED $^{\circledR}$ for Homes with similar expectations but no requirements for comprehensive durability. 
Although the efficacy of LEED $\AA$ is continually being observed, debated, and revised, the system has a long ways to go if real substantive results are expected. The USGBC conducted a study last year and found that $53 \%$ of LEED $\AA$ certified buildings did not qualify for the Energy Star label, another rating system in the U.S., and that $15 \%$ scored below 30 in the Energy Star program, meaning that they used more energy than at least $70 \%$ of comparable extant buildings. The best performing buildings were smaller and had less glass, which should surprise no one [4]. The reliance on rating systems such as LEED ${ }^{\circledR}$ exemplifies what Reese has labelled the "mass-delusion in consumer culture."

We are inundated with "sustainable" building products to the point that designers and owners have a difficult time separating fact from fiction. Brick is touted as a durable material that comes from the earth. Glass towers receive LEED ${ }^{\circledR}$ accreditation. Does a truly sustainable building material exist when we define sustainable as conserving an ecological balance by avoiding the depletion of natural resources?

\section{Natural materials}

The few renewable and/or easily biodegradable or reusable resources used as building materials are found in a group of natural materials either mineral (nonrenewable) or organic (renewable) in composition and comprised of stone, earth, grasses, and trees. These materials have been used for constructing buildings throughout history leaving a rich vernacular legacy of earthen homes, thatch covered roofs, stone structures, and log houses to name but a few. Most of the uses were born of necessity for shelter and were dependant on availability of the material. Following is a brief discussion of how these materials are presently used in exterior wall construction.

\subsection{Stone: veneers}

We no longer use stone as a load-bearing construction material. It is a finish, a cladding producing a pleasing aesthetic and the image of durability. Stone is commonly quarried on one continent, shipped to another for fabrication, and then finally put in service in North America. Stone cladding systems are not easily reused and durability not always what it seems. As stone is sliced thinner and thinner its inherent structural capacities are reduced. Note the failure of the Carrara Bianco marble that clad Alvar Aalto's Finlandia Hall (1972) in Helsinki. Although concerns were raised about this marble being a suitable cladding material for a building in Finland's climate, they were ignored. New technology had allowed for the fabrication of thinner pieces of marble than previously. The marble began to permanently warp severely within a few years of the building's completion and eventually had to be replaced. The citizens' of Helsinki voted to replace the failed marble with the same Carrara Bianco with a better attachment system. This new cladding started to warp within six months of its installation due to hysteresis. Thin $(25-38 \mathrm{~mm})$ crystalline marble slabs will permanently and cumulatively deform, with a corresponding loss of strength, due to thermal 
expansion and moisture ingress, a phenomenon known for many decades. It is not unreasonable to suggest that the marble cladding of Finlandia Hall will need to be replaced again in another 25 years or so. The embodied energy of this cladding is multiplied by a factor of four when one considers that the expected lifespan of stone has been reduced by a similar factor [5]. Stone can now be sliced as thin as $10 \mathrm{~mm}$. This thin slice is bonded to a stabilising panel of aluminium honeycomb, reducing weight and cost. But the durability of such systems should be seriously considered.

\subsection{Grasses: straw boards, straw bales, bamboo}

Of recent interest is the use of straw and bamboo in buildings. While bamboo is a quickly renewable grass, straw is a waste product from a variety of grains including, but not limited to, wheat, oats, barley, rye, and also rice. There are few uses for straw other than animal bedding and landscape covering. In many areas it is burned in the fields severely affecting local air quality. Straw can be pressed into structural boards that replace standard western platform framing or " $2 \times 4$ " construction. The product is extruded under heat usually around $200 \mathrm{dc}$ (400df) and pressure. The process uses minimal energy to produce the highly dense, fire-resistant board. The compression releases natural resins that bind the straw together. Straw boards from Agriboard Industries, in the United States, were used as exterior walls in the Bank of America building in Frisco, Texas, helping to create a building with a negative carbon footprint. Four weeks of construction time was saved, which lowered construction costs, and the steelframed building was enclosed in six days [6].

Straw is also used as a wall system of stacked bales usually with a wood postand-beam structural system. This system requires carefully baled straw, typically 450-600 mm (18-24 inches) in depth. Perhaps the biggest problem is that the straw must remain dry during storage, transportation, and installation. It is also advantageous to wait until the straw has compressed before weatherproofing the exterior. All of this adds to construction difficulties and extends the construction time. Straw bales have been used historically along with sod blocks for construction, but it is a material that may not make the translation to a sustainable way of building for the future, except in limited geographical areas.

Bamboo is emerging as a possibility for a quickly grown raw material with inherent structural properties. Much experimentation is occurring with laminating this fibre into claddings, sheathings, and floor coverings. Because of its fast growth, bamboo may fill construction requirements more easily than trees. It is not commonly used as a structural building material except in small houses and as scaffolding or similarly framed constructions. This may well be a material with future potential as the structural and moisture-resistance properties are more fully realized.

\subsection{Earth: sun-dried brick, compressed earth blocks, fired-clay brick}

The first "building product" was the sun-dried brick produced 10,000 years ago. Historically houses have been constructed of earth in various forms from sun- 
dried brick to rammed earth walls. Today approximately one-third of the world lives in houses constructed of earth. In developing countries it is over one-half [7]. Sun-dried brick or adobe is still used for construction in the southwestern United States. Fired-clay brick is the outgrowth of sun-dried brick. Concrete and other cementitous materials are often deemed to be materials of the earth; however the energy expended to produce cement removes these products from a list of truly sustainable building materials.

Brick is a material that exudes durability, an implied sustainability of the product. But fired-clay bricks may not be the sustainable product manufacturers would have us to believe. The majority of "brick" buildings have only a single veneer wythe, frequently with a back-up wall of light-gauge steel studs. The brick serves merely as a cladding, albeit a heavy one. Rarely is the load-bearing capacity of fired-clay brick utilized in Canada or the United States. When the propensity for failure of this single-wythe veneer is considered, the argument for brick being a sustainable material is further maligned. The Brick Industry Association's (BIA) Technical Note 48, titled Sustainability and Brick, states, "Brickwork is durable, having a life expectancy of hundreds [author's emphasis] of years. Brick buildings can be and are reused..." [8]. These are not "brick buildings" but rather buildings clad with brick. The problems with brick claddings are widespread in the United States and Canada. The author's masonry forensics firm spent over a decade studying anchored brick veneer failures and designing solutions on primarily institutional buildings. A University performing arts centre illustrates the problems with this cladding in the U.S. and Canada. The building has a cast-in-place concrete load-bearing wall that was clad with anchored brick veneer. First occupied in the mid-1970s, problems were noticeable within a few years. When the author first observed the building had been in service less than 15 years. After a lengthy investigative period it was determined that the brick veneer would need to be replaced. Insufficient horizontal and vertical expansion joints and inadequate anchorage of the veneer and its supporting shelf angles were the primary problems [9]. A design architect was hired to work with the exterior aesthetics of this prominent building. The very carefully researched and designed new veneer was then analyzed through a value engineering process required by the State. The University had expressed a desire for a 100-year cladding. Designing and constructing a 100 -year brick veneer cladding is possible but unlikely given the cost and design restrictions. With compromises made through working with the design architect and the value-engineering process the author determined that the estimated life was 75 years. The cost of replacing anchored brick veneer on this relatively new building with anchored brick veneer was over $\$ 7.5$ million in today's U.S. dollars.

Reusing brick is also questionable. As the BIA states in Technical Note 15: “... it may be next to impossible to salvage brick from modern structures which use brick set in Portland cement mortars... It is virtually impossible to completely clean these [cementitious] particles from the surfaces of the brick units. This may greatly affect the bond between brick and mortar when reused." [10]. 
The most sustainable use of the earth in contemporary practice may be in creating earthen blocks whether they are sun-dried brick (adobe) or pressed earth blocks. These materials can at minimum be returned to the earth. They can also be reused and the fossil flue used in production is minimal.

\subsection{Trees: plantation trees and engineered wood}

In Canada and the United States wood is used extensively in the popular and economical, western platform framing, or "two-by-four" or "stick-built" construction as it is sometimes called. This system, using dimensional lumber and wood sheathing, produces a quality structure for minimum cost. It can be used in housing developments up to six stories in height in Vancouver, Canada and five stories on a one or two-story, non-combustible base, in Seattle, U.S.A. The flexibility and economy of scale make it a highly competitive structural system. It is unlikely that the basic method of construction will radically change in the housing industry in the very near future. The author has investigated the use of this system in Japan, Chile, and Switzerland, as an economical method of meeting current housing needs. Other systems consist of solid wood walls formed by laminating smaller pieces of wood into structural panels. These are more prevalent in Europe.

Trees regenerate, but wood is a limited renewable resource at the rate deforestation is occurring in many countries. Although there are numerous products that use wood fibre and waste from milling, the desirable woods from hardwoods, structurally sound softwoods such as fir, and decay resistant woods such as cedar and redwood can hardly be called renewable resources. Wood acts as a carbon sink, an advantage that underscores the need for durable wall systems. And wood is durable when protected. The Norwegian stave churches, some of which are close to 1000 years in age are good examples. The wood cladding has been replaced, but the original structures are intact.

Timber that is grown quickly on plantations may be the best renewable wood resource to date. However even this wood can carry a high-environmental cost in waste, product production, transportation, disposal, and loss of natural ecosystems. As these are weaker trees and smaller in diameter, smaller pieces of wood are often laminated using glues and resins creating engineered wood.

\section{Sustainability and houses}

Most efforts in making housing more sustainable emphasize alternative ways of producing energy or methods of increasing performance of the building envelope. The discussion focuses less frequently on reducing the embodied energy of the structural components or increasing the life span of the building. Is it possible to use materials that are truly renewable and durable? Are they still sustainable when the procurement of raw materials, manufacturing processes, and transportation, followed by the ecological cost of maintaining, and finally recycling or reusing the materials, are considered. Equally important is the 
continuing purposefulness with cultural and economic changes. The following discussion focuses on engineered wood and earthen blocks.

\subsection{Engineered wood}

A Japanese housing manufacturer, KST-Hokkaido, offers an interesting look at a sustainable house using engineered wood in a broader context. Although the company no longer manufacturers houses, the model is worth reviewing. Hokkaido, the northern most the archipelago that makes up Japan has almost a quarter of Japan's land mass but only $5 \%$ of the population, making detached homes more viable. The KST-Hokkaido House was a hybrid of structural post and beam pre-cuts, prefabricated panellized walls, and on-site construction that was uniquely designed for this specific region and culture. The design of this simple house was the culmination of over fifty years of experimentation by the KST-Hokkaido founder and owner, Mr. Akira Yamaguchi. Although the KSTHokkaido House attracted the interest of researchers from around the globe, the house was never exported even to the northern regions of Honshu, which has a similar climate. It was designed specifically to meet the environmental and social needs of Hokkaido residents.

Because Yamaguchi felt strongly that the multigenerational family was important to the sustainability of Hokkaido's society, he developed a housing form to support this family relationship. As a result of the harsh winters, construction often stopped for up to six months of the year in Hokkaido. Yamaguchi believed that the year-round construction of houses was important for the community. He also noted that the highly specialized temple carpenterwho stressed quality and respect for materials - could never meet the post war production needs for housing. During this period he observed and experimented with the "two-by-four" construction used by American companies in the area. He noticed the benefits of using modular pieces that could easily be assembled by unskilled workers. He also recognized that poor-quality housing was a major problem in Hokkaido as in the rest of Japan. To keep costs down and still maintain quality, he started prefabricating as much of the KST-Hokkaido House as possible in a factory with each worker performing only a few tasks using precision equipment in an assembly-line fashion, providing year round employment. Emphasis was on durability, creating a 200 -year house where the typical Japanese house lasted only 26 years [11]. In an interview between the author and a grandmother who had recently purchased a KST-Hokkaido House for herself and her son's family, she stated she chose the house because of its "durability."

Perhaps Yamaguchi's greatest concern was a respect for the natural environment. He remarked that his "mind was always on wood and winter in Hokkaido." In following this philosophy, Yamaguchi tried to use only local wood, much of it engineered from smaller pieces. This combination of modern industrial house-building techniques and traditional values made the KSTHokkaido House distinct [12].

The author followed the KST-Hokkaido House for over a decade. Unfortunately the company was unable to weather the departure of $\mathrm{Mr}$. 
Yamaguchi from the company in combination with the aftermath of Japan's economic bubble. This model for sustainable living and working required the strength, focus, and vision of a person such as Mr. Yamaguchi.

Making use of excess local woods is worth the effort, but it usually is only a stopgap strategy that will eventually peter out. Recently a scourge of pine beetles, most likely due to the effect of global warming, has killed a large swath of tress in Canada and the United States. This wood is usable if properly processed. While this is not sustainable, looking at methods of using that which is waste should be a high priority.

Wood, from plantations, is one of our few renewable resources. If the environmental concerns can be addressed and non-toxic binders developed then engineered wood products from plantation trees may make a difference. Utilising the engineered wood to its maximum, decreasing the size of housing units, and emphasizing durability might mitigate the sustainability concerns about wood. Added to the list of engineered products might be straw boards and laminated bamboo. Reusing or recycling these products may be difficult but there is no reason why a structure of wood cannot last 200 years if properly designed and maintained. And a house of wood is also the cultural expectation in Canada and the United States.

\subsection{Earthen blocks}

As previously noted, using fired-clay brick as a cladding makes little sense environmentally. But what about using earthen blocks as structure? Adobe or sun-dried bricks and compressed earth blocks both have potential in modern construction. (This discussion does not include rammed earth or cobb construction, similar construction types with many of the same attributes as adobe brick.) Blocks of earth have low embodied energy and when used in a properly designed wall are very durable. With frequent maintenance adobe can last for centuries. The six-story, Taos Pueblo in northern New Mexico U.S. has been continuously occupied for over 500 years. This construction method is being resurrected in the Southwest of the United States. The earth blocks have aesthetic, acoustical, and thermal advantages over many other construction types, particularly for housing. While many small operations exist, there are also larger commercial producers of adobe brick. Typically the "loam" used in adobe construction is a mixture of clay, silt, sand, and sometimes larger aggregate. Clay acts as a binder similarly to cement in concrete. Fibre such as cut straw is added as reinforcing to reduce shrinkage cracks in the blocks. Additives can be added to increase the performance of adobe. These include artificial stabilizers such as synthetic resins, mineral and animal products, cement, lime, and bitumens [13]. Numerous field and laboratory tests can establish the right mixture for the given application. The diurnal thermal change in the houses with adobe walls is much less than in houses of wood frame construction. Modern applications to walls can create durable and pleasing interior and exterior surfaces. And demolition of the material is easy, the earth returns to the earth. In New Mexico, factories produce traditional adobe bricks of blended soils with straw for reinforcement. They also produce semi-stabilized blocks that have 4- 
$5 \%$ asphalt emulsion, and fully stabilized blocks with $8-10 \%$ asphalt emulsion, which according to the New Mexico Code can be left exposed. Although not part of model codes to date, New Mexico has a "New Mexico Earthen Building Materials" Code that covers various methods of building with earth. The author visited one structure that was being restored in New Mexico. There had been a fire in the 70-year-old building that destroyed the wood roof and floor joists. Approximately two-thirds of the walls were standing. Some had fallen because of lack of protection from the weather for the last 20 years but some of 70 yearold adobe blocks were salvaged for use in the repair. The remaining brick were being produced on-site with locally sourced materials including some of the disintegrating adobe brick.

Is this a viable method of construction? One can certainly argue that it is sustainable. Perhaps an even better use of loam or soil is using it in compressed earth blocks. The Cinva Ram became popular worldwide in the 1950's as a method of producing a structural block using local materials and requiring only human power. Although cement made the blocks stronger, binders such as eggs and cow manure were also used with straw serving as reinforcing. The latest generation of these simple rams have compressors fuelled usually by propane or gas that compacts the earth, adding considerable strength when compared to those produced with the manual press. Some companies have been experimenting with adding waste materials such as gypsum wallboard to the mix. The GreenMachine manufactured by TerraBuilt can produce 4-5 brick per minute. In 20 to 24 hours enough brick is produced for a 100 square meter house. They can be made of $100 \%$ loam or up to $8 \%$ cement can be added to increase the compressive strength and resistance to moisture. In a certified independent testing lab it was found that the Terra Bricks exceed the New Mexico adobe compressive strength standard of 300 psi, measuring from 900 to 2,240 psi depending on cement content. They also out performed the adobe wall standards for modulus of rupture, lateral loading, and shear strength. The Oakridge National Laboratory Building Technology Center ran thermal dynamic tests that showed a properly engineered TerraBuilt wall significantly out performs an equivalent wood frame wall system [14].

Additional benefits of earthen blocks are their low moisture content that allows for contact with wood, their ability to absorb pollutants, and their capacity to store moisture and heat.

\section{Conclusions}

If we ever adopt an aggressive attitude towards stopping the overuse of natural resources and try to start reversing the cumulative damage, engineered wood and earthen blocks may play a role. This requires a paradigm shift in the way we understand our homes. Housing may take more labour to construct and require more frequent maintenance. There should be an expectation that houses will last 100 to 200 years, which means neighbourhoods need to be preserved. Our attitude of everything, including our buildings, being disposable needs to stop. The amount of space required for living should be challenged. None of this 
implies a lower standard of living, just a different standard. The status quo may not be maintained but the quality of our lives need not decrease.

\section{References}

[1] Reese, William E. The ecological crisis and self-delusion: implications for the building sector, Building Research \& Information, 37: 3, pp. $300-$ 311, 2009.

[2] Mazria, Edward, It's the architecture, stupid! Solar Today Magazine, pp. 48-51, May/June 2003.

[3] Davies, Colin. The Prefabricated Home, Reaktion Books Ltd: London, p.8, 2005.

[4] Navarro, Mireya. Some buildings not living up to green label, New York Times, August 31, 2009.

[5] Brock, Linda. Designing the Exterior Wall: An Architectural Guide to the Building Envelope, John Wiley \& Sons Inc: Hoboken, New Jersey, pp.264270, 2005.

[6] Agribond, http://www.agriboard.com/

[7] Minke, Gernot. Earth Construction Handbook: The Building Material Earth in Modern Architecture, WIT Press: Southampton, p.9, 2000.

[8] Brick Industry Association. Technical Note on Brick Construction, Sustainability and Brick, \#48, June 2009.

[9] Brock, Linda. Designing the Exterior Wall: An Architectural Guide to the Building Envelope, John Wiley \& Sons Inc: Hoboken, New Jersey, pp.274, 2005.

[10] Brick Industry Association. Technical Note on Brick Construction, Salvaged Brick, \#15, May 1988.

[11] Cole, Raymond, Lorch, Richard, eds. Buildings, culture and Environment: Informing Local and Global Practices Blackwell Publishing: Oxford. p.318, 2003.

[12] Brock, Linda. Designing the Exterior Wall: An Architectural Guide to the Building Envelope, John Wiley \& Sons Inc: Hoboken, New Jersey, pp.323332, 2005.

[13] Minke, Gernot. Earth Construction Handbook: The Building Material Earth in Modern Architecture, WIT Press: Southampton, p.9, 2000.

[14] TerraBuilt, http:/www.terrabuilt.com/index.asp 